\title{
Article
}

\section{The role of specially designated wildlife sites in freshwater conservation - an English perspective}

\author{
${ }^{*}$ Chris P. Mainstone \\ Natural England, Northminster House, Peterborough, Cambs, PE1 1UA. Email: chris.mainstone@naturalengland.org.uk \\ * The views expressed in this article are those of the author and do not necessarily reflect Natural England policy.
}

Received 20 November 2007; accepted 30 January 2008; published 11 March 2008

\section{Abstract}

The value of specially designated sites in conserving biodiversity has been a hotly debated issue for many years in the UK and elsewhere. The debate recently has been given fresh impetus in England by the creation of Natural England, the new Government Agency responsible for the protection and enhancement of the natural environment, and the challenges facing the management of designated sites resulting from the increasingly tangible effects of climate change. In the freshwater environment, the role of designated sites is under a particular spotlight because of the implementation of the European 'Water Framework Directive', which aspires to holistic, ecologically based management of aquatic habitats.

This paper explores the underlying premises of, and rationale for, special site designations for wildlife and provides a frank account of the inevitable clash of management philosophies that designations create in the freshwater environment. It draws on experiences of managing designated freshwater sites in England over the past decade from within English Nature, the former statutory agency for nature conservation (succeeded by Natural England). The issues and principles discussed, are however, highly relevant to the rest of the UK, other European Member States and countries further afield.

A positive role is outlined for designated sites in freshwater conservation, which addresses these management conflicts in a way that not only meets Government obligations towards these sites but also paves the way for informed, progressive management of the wider freshwater resource. As part of this account, attempts are made to clarify the relationship between key biodiversity-related policy drivers in the freshwater environment and to explain how the spectre of climate change can be addressed within designated site management. The importance of strategic freshwater science, collaboratively designed and funded, in maximising the value of the designated freshwater site network to the wider freshwater habitat resource, is stressed.

Keywords: Catchment management; freshwater management; protected sites; SSSIs; habitats directive; Water Framework Directive. 


\section{Introduction}

The Government Agencies responsible for nature conservation in the UK have been criticised over the years for the level of attention paid to the protection of sites with special designations for wildlife. There is a body of opinion that designated sites serve only to deflect resources away from the protection and restoration of wildlife in the wider countryside, and that the concept of designated sites is an anachronism, particularly at a time when dynamic management of habitats is needed to adapt to climate change. Leaving aside the clear statutory obligations towards these sites imposed by national, European and international legislation, there are very logical and progressive reasons for maintaining a focus on the designated site network, albeit properly nested within a broader strategy for wildlife conservation and the enhancement of the natural environment. This situation is exemplified nowhere better than in the freshwater environment.

The argument that designated sites act as a source of 'seed' populations of species, to re-establish the biodiversity of the wider landscape when environmental conditions are restored, is well rehearsed (e.g. Usher, 1989; Phillips, 1996). A key weakness of this argument is that it does not help to explain how these favourable conditions will come about outside the designated site network, or contribute to this desired outcome. In the freshwater environment, there is a huge inertia to putting in place management plans truly capable of rectifying the problems associated with such complex environmental issues as eutrophication, siltation, physical habitat degradation, and abstraction-related stress. Most of this inertia is generated by the sheer scale and, therefore, potential management costs of the problems to be addressed. As will be discussed later, the management implications extend far beyond the confines of freshwater habitats into the furthest reaches of their catchments. The often used management approach of ratcheting up the pressure gradually on different sectors of human activity in order to improve their performance (as exemplified by the European Commission (EC) 'Urban Waste Water Treatment Directive' and the 'Nitrates Directive') and thereby to move the environment in the right direction, is a slow process and one in which the ultimate end-points for both sectors and wildlife are left ill defined. While there is a general desire by most parties to move to a transparent management framework with clear, stable and ecologically appropriate targets, at times this seems a distant goal.

This paper seeks to explore the concept of designated sites and to outline how designated freshwater sites can be used to break down the inertia to strategic, ecologically based freshwater management, such sites providing a demonstration of positive management action and a platform for learning about appropriate management approaches in the wider freshwater network. The thinking is based upon experiences with designated freshwater sites in England over the past decade. The generic issues and principles described, however, are common to all countries that are grappling with the protection of freshwater biodiversity. In particular, the European Union shares common legislation for designated wildlife sites (the EC 'Habitats and Species' and 'Birds' Directives) and the general protection of the freshwater environment (the EC Water Framework Directive), so the parallels are extremely close.

\section{Observations on the basis for designated site legislation}

At the highest level of generalisation, the basic premise that underlies protected area legislation (at national, European and international scales) is one in which pristine (or nearly so) exemplars of habitat can be identified and designated, within which adverse human pressures can be excluded or maintained at currently very low levels. To a freshwater ecologist, this premise seems geared towards terrestrial habitats that can be fenced off from surrounding land, with the condition of the site dependent on the management regime within the perimeter fence; any activities that operate outside the fence have little or no relevance (even here, air pollution threatens the validity of the premise).

In situations in which this premise is valid, protection of designated sites essentially concerns avoiding any deterioration from existing conditions. The process of protecting against possible future damage is easier (though 
not necessarily easy in an ever-developing world) to achieve in societal terms than the restoration of habitats from existing impacts. This situation arises because existing impacts are often linked intrinsically to existing socioeconomic well-being and/or carry high costs of management intervention. In contrast, possible future damage is generally related to one possible future socio-economic status. Certain types of economic growth within and near a designated site may be constrained, but generally there is no significant effect on the existing socio-economic picture.

Unfortunately, in England, as in other parts of both the developed and developing worlds, freshwater habitats are affected extensively by a range of human activities. While major strides forward have been made in recent decades in England in the control of gross organic and toxic pollution, mirrored in many European countries, a range of more insidious impacts, such as eutrophication, siltation, abstraction stress and physical habitat degradation, becomes revealed. Considering the long-standing nature of many of these impacts, the relatively late designation of freshwater sites, and the difficulties in controlling activities occurring in the catchments of designated freshwater sites, it follows that these widespread impacts are inevitably present in the designated site network. This situation generates two 'body blows' to the basic premise underlying designated site protection:

1. Designated freshwater sites are often not in a nearpristine state;

2. Management action to rectify problems is not confined to the area lying within the site boundary (which for freshwater sites is generally positioned on the land/ water interface), but extends out to a much larger area delineated by the catchment of the site.

This situation leads to an understandable management dilemma. The activities of agencies responsible for the general protection of the aquatic environment (the Environment Agency in England) are driven strongly by the requirement to balance the needs of the environment with the needs of society through costbenefit considerations. Designated sites that are in a near-pristine state are easier (though not easy) for these agencies to deal with, as the costs of keeping them pristine are generally low in relative terms and existing levels of human activity can be maintained. Where designated sites are already affected, however, the costs of restoration can weigh heavily and acute conflicts can arise between general duties towards sustainable development and specific obligations towards specially designated sites laid down in the legislature. While legal mechanisms exist for recognising 'immovable' anthropogenic impacts on designated sites (such as the concept of Over-Riding Public Interest in the EC 'Habitats and Species Directive'), the general presumption is that these should be used only sparingly (again perhaps reflecting a near-pristine, terrestrial perspective on designated wildlife sites).

This dilemma often manifests itself in bureaucratic attempts to 'square the circle' - calls are made for the management objectives of such sites to be the maintenance of the condition of the site at the time of designation, even though there are often considerable pre-existing impacts that clearly need to be addressed. An alternative argument is that freshwater sites with pre-existing impacts should not be designated at all or, if already designated, should be denotified (on the basis that they are degraded and/or no better than other examples of the habitat). Arguments that revolve around this type of administrative solution serve only to mask the environmental problems facing fresh waters, deny the obligations under designated site legislation to rectify these problems, and delay appropriate management action.

It is interesting to note that this dilemma forms part of a wider dynamic in the relationship between the protection regime for the designated site network and the protection regime for the wider environment. The lower the level of ambition of society in addressing environmental problems in the wider environment, the more important are special site designations in adequately protecting a representative sub-set of the habitat resource and demonstrating this level of protection to society. Conversely, the more progressive and ambitious the protection regime for the wider environment, the less reliance needs to be placed on designated site legislation. In the USA, for example, a high level of protection (through non-intervention) is afforded to large-scale national 'wilderness' parks. The 
basic level of legal protection for freshwater biodiversity, however, is arguably lower than in the European Union, in which the Water Framework Directive provides (at least in principle) a more stringent legislative framework.

\section{The history of site designations in England's fresh waters}

The discussion above begs the question: How are operational decisions made about designating sites and particularly freshwater sites? The answer to this question could easily be the subject of a separate paper, but a brief explanation is attempted here. A more detailed account of the history of designating freshwater sites in the UK is provided in Boon (1991).

There is a long history of designating wildlife sites in England, but the modern era of strategic designation started with the UK Nature Conservation Review (Ratcliffe, 1977). Under the review process, sites were selected for designation based on a series of 10 criteria, some of which (such as 'representativeness' and 'naturalness') have been the subject of heated debate ever since. Following the review, specific technical designation criteria were developed for different habitats and species assemblages (JNCC, 1989), which have been applied to generate the national network of Sites of Special Scientific Interest (SSSIs) that we have today. Significantly for fresh waters, the designation of rivers was placed on a strategic footing in the early 1990s, with the notification of a series of 'whole-river' (source-to-sea) SSSIs covering the range of river types encountered in England.

On top of these nationally driven processes of site designation, various European and international designations have been applied to sites, including Special Areas of Conservation (SACs) under the EC Habitats and Species Directive, Special Protection Areas under the EC Birds Directive, and Wetlands of International Importance under the Ramsar Convention. These carry their own various criteria for site designation, including lists of priority habitats and species and requirements to designate sites across the geographical range of each feature.

A frequently asked question in freshwater management circles is: why is one site (typically referring to a river) designated when a seemingly similar site in a seemingly similar condition, immediately adjacent to the designated site, is not? It is important to understand that not all sites that are worthy of designation are designated. Representativeness is a key selection criterion for SSSIs and also for SACs - sites designated for their habitat are typically chosen to be representative of a habitat type within a locality or nationally, ensuring that at least a small part of the habitat resource is subject to special consideration and stronger protection.

A further question asked about the designation of freshwater sites is: how can a site be worthy of special designation if it is already impacted by a range of human activities? Site designation processes, both national and international, require the designation of 'best examples of type'. Where no pristine or near-pristine examples exist in a locality, this inevitably means the selection of sites that are impacted to a greater or lesser degree. This message was 'brought home' forcefully in recent years by the European Commission's sequential reviews of the SAC network in the UK (the so-called 'Moderation Exercise' - McLeod et al., 2005). In relation to rivers, these reviews required additional designations for river habitat and priority riverine species in the east of England, where no designations had originally been made due to the extensive and serious impacts on the river network in this part of the country.

\section{Designated sites - a force for progressive management of the freshwater environment}

In the freshwater environment, ecological problems are frequently the result of a complex interaction between different human pressures and different impacts on ecosystem processes. Teasing apart the contribution to these problems from different sectors of human activity can be a difficult process, leading to equivocation about which sectors should be held responsible and to what degree. Investigations can lead to delays of many years before they can inform management and it is often the case that such investigations lead to yet more questions that need to be answered before the work can be used in a management context. In these circumstances, it is often 
necessary to undertake strategic management action in certain catchments to further our understanding of what management action is required to address generic environmental problems.

The policy drivers behind designated site legislation inevitably require management action to be taken in order to control adverse anthropogenic effects in advance of more widespread, and hence costly, control of similar effects in the wider environment. In parallel, a more environmentally precautionary approach is required to decision-making in the face of scientific uncertainty - a different balance is struck between the risks to the environment and the risks to human activities to that struck in the wider environment. Conventional cost-benefit analyses applied to the wider environment do not apply to designated sites - more costly action can be justified on designated sites because of their additional legal status and (more pragmatically) because of their limited spatial extent relative to the wider environment.

Against this backdrop, it is possible to envisage two contrasting approaches to the management of designated freshwater sites.

A regressive approach. This approach involves trying to ignore the special legal status of designated sites, playing down the nature of ecological problems, failing to recognise the conservation objectives of these sites, equivocating over appropriate action (including which sector should take action first), and generally delaying a management response until it is no longer possible to do so (for example, because of the threat of infraction under the EC Habitats and Species Directive). This is not an approach that any civilised and prosperous country should consider. A progressive approach. This involves using the additional drivers that designated site legislation provides to identify and implement all necessary strategic action in the catchments of designated sites, based on best scientific judgement. This action is used not only to meet designated site obligations but also to improve our scientific understanding, inform the development of decision-making processes for the wider environment, and provide a demonstration of what is achievable through a positive, strategic approach to environmental protection and wildlife conservation.
At the heart of the progressive approach lies a need for transparent and honest assessments of impacts on designated sites and of the management costs of removing them, which lead to frank and open discussions about affordability. A clear separation of judgements of ecological impact and judgements of affordability of management action is needed if we are to progress our understanding of the management strategies that we need to adopt, both for designated sites and in the wider environment. A blurring of these judgements leads to inadequate management strategies that will require modification later - a potentially damaging situation not only for freshwater wildlife but also for those needing to make major business investment decisions. Genuine problems of affordability of management action on designated sites can be dealt with in various ways, including extending the deadlines for completing the action required when this can be shown to be justifiable.

The processes developed in England for defining appropriate management action for designated freshwater sites, based on the definition of Conservation Objectives for each site and the application of Limits of Liability (LoLs) to different sectors, are summarised in Mainstone \& Clarke (in press). These processes are based on a compartmentalised approach to tackling the effects of multiple anthropogenic pressures, an approach that facilitates timely decisions over appropriate management action.

Considering the representation of freshwater habitat types within the SSSI network, the scope for establishing strategic R\&D (research and development) to understand better the response of critical ecosystem processes to strategic management action is clear. Such R\&D is vital for underpinning future management strategies in the wider freshwater environment - this is discussed further below.

The progressive approach to the management of designated freshwater sites extends beyond the restoration of freshwater habitats into the practical realisation of multiple environmental and societal objectives connected to water and catchments. Sympathetic management of designated freshwater sites and their catchments provides major opportunities for the targeted re-creation of seminatural terrestrial habitats, catchment-based approaches to 
flood risk management, enhanced groundwater resources through improved rainfall infiltration to aquifers, improved drinking water quality, better landscape quality and recreational opportunities, and improved tourism potential. Securing and demonstrating these types of ecosystem services, drawn from a healthy freshwater environment, will be vital in strengthening the case for strategic action on the wider freshwater habitat resource.

\section{Integrating action with the other key policy drivers in freshwater management}

Protection of designated freshwater sites sits within a wider set of environmental policy drivers. At a broad level, these other drivers can be categorised into:

1. Protection of the freshwater environment, for its own sake and for the resources it provides to society; and

2. Protection and enhancement of biodiversity, within which designated wildlife sites can be considered a key element.

Within England, these broad categories are populated by:

1. The EC Water Framework Directive; and

2. The UK Biodiversity Action Plan

- these are discussed below in turn.

It might be considered surprising to write at length about the management of the freshwater environment within a Member State of the European Union without focusing on the EC Water Framework Directive (WFD). In recent years, the implementation of this Directive has become synonymous with the achievement of all of society's aspirations for the freshwater environment, as indeed it was intended to be. Practical constraints, however, have bitten hard as plans for implementation have developed, and the limitations of using the WFD to achieve these aspirations (at least in the short term) have become increasingly apparent.

As implemented in England, most headwater streams (defined as streams with catchments of less than $10 \mathrm{~km}^{2}$ ) and small-/medium-sized lakes (defined as less than 50 hectares of water) will not form part of recognised 'water bodies' (the basic management unit within the WFD) and will, therefore, have no direct protection under the Directive (although they will benefit from any action to protect recognised 'water bodies' located within the same catchment). Within recognised water bodies, many basic environmental standards that are being established to protect 'Good Ecological Status' (GES), the basic level of protection afforded by the WFD, are considered by the author not demonstrably adequate to control the ecological impacts they are intended to protect, particularly considering the intended model for their application (see http://www.wfduk.org/stakeholder_reviews/ for information on the proposed standards and stakeholder comments on them). While the objectives of a range of specially 'Protected Areas' are included in the terms of the WFD (covering areas designated under various European Directives such as the 'Drinking Water' and the 'Freshwater Fish' Directives and including waterrelated SACs designated under the Habitats and Species Directive), the objectives of nationally designated sites, such as SSSIs, are not covered.

These exclusions highlight an important paradox in the implementation of the WFD. The Directive defines a range of environmental objectives for the aquatic environment and an integrated management-planning framework to achieve those objectives. This planning framework is set to supersede the catchment-planning framework already in place in England, yet the WFD does not cover all environmental objectives for which strategic catchment planning is necessary. This paradox is yet to be resolved and is proving to be a major source of confusion to those with an interest in integrated catchment management. Confusion extends beyond the planning framework to the definition of individual regulatory instruments to control certain types of impact on the freshwater environment (e.g. diffuse pollution). Any new instruments that are specifically linked to the achievement of WFD objectives may not be available to be used to achieve environmental objectives outside of the requirements of the WFD.

Action in England under the first round of WFD management planning (from 2009 to 2015) seems destined to be modest and focused on securing appropriate management of Protected Areas. The questionable level 
of precaution in the technical specification of GES and supporting environmental standards in the UK, driven by inevitable concerns over the scale of implied management costs, makes the separate and independent judgement of the condition of designated wildlife sites ever more important.

Nevertheless, it is not necessarily all 'doom and gloom'. There is an opportunity to test out strategic and innovative management approaches within the limited spatial extent of the designated site network, through the first WFD management planning cycle, in a way that informs management strategies for the second cycle in 2015-2022. Detailed, process-based science can be established in the catchments of these sites that can underpin any changes required to the technical specification of GES and supporting environmental standards, while the gradual ratcheting up of environmental performance in the wider environment will continue in the first WFD management cycle through the application of currently proposed standards.

The UK Biodiversity Action Plan (UK BAP) was first established in 1994 to fulfil UK commitments to the Rio Convention on Biological Diversity, to which it was a signatory in 1992. The recent UK review of BAP priority habitats and species (UK BAP, 2007) has triggered fresh debate about the role of the UK BAP in freshwater conservation. The review resulted in the specification of new priority habitats in fresh waters, comprising all natural river types (not just chalk rivers as was previously the case), oligotrophic lakes (adding to the current priority habitats of naturally eutrophic and mesotrophic lakes so that all lake types are now covered), and ponds. This specification is in addition to the wide range of freshwater wetland types (fens, bogs and reed beds) already defined as priority habitats under the BAP. The ever-increasing list of UK $\mathrm{BAP}$ priorities places considerable strain on existing BAP implementation processes, considering that these processes were really developed for a relatively small number of habitats and species with limited spatial occurrence.

In the freshwater environment, there are pragmatic means of dealing with the UK BAP dilemma of burgeoning priorities. The UK BAP Steering Group has already recognised a general and urgent need to resolve actions (wherever possible) for the huge number of priority species into action plans for the priority habitats on which those species depend. This approach is fundamental not only to make the UK BAP a practical proposition but also to address the problem of adaptation to climate change within species conservation. In respect of freshwater habitats, however, a second opportunity for managing the BAP dilemma presents itself in the form of the WFD. The WFD provides a general regime for the management and protection of the freshwater environment, on which considerable resources will be spent; however, it is not clear to what extent WFD objectives for ecological status (and associated action) will meet UK BAP objectives for priority habitats and species. In respect of freshwater habitats, a suitable role for the UK BAP could be, therefore, to act as an auditor of the extent to which action under the WFD meets BAP objectives, and as an instigator of action beyond basic WFD measures (particularly for achieving GES) when this is required.

Fig. 1 attempts to illustrate how the three key policy drivers for protecting freshwater habitats in England (designated site legislation, WFD and the UK BAP) interact with each other in practice - a sort of Grand Unifying Theory for freshwater conservation. While the UK BAP is an umbrella for all action on BAP priority freshwater habitats (including rivers, lakes and wetlands), the added value of BAP as a separate policy driver comes from securing action for priority habitats beyond that necessary to implement designated site legislation and basic WFD objectives. The greatest synergy between these drivers is achieved by making action on designated sites and the WFD as receptive as possible to UK BAP objectives, maximising the degree of overlap in Fig. 1, but there will always be activities in fresh water that will fall to the UK BAP alone.

Some of the most obvious areas for the UK BAP to focus its scrutiny are freshwater habitats that are not adequately covered by WFD 'water body' status (lakes less than 50 hectares, headwater streams and surface water-fed wetlands). There are also potential shortfalls, however, in types of management activity under the WFD that might need to be plugged more generally within WFD water bodies to satisfy the needs of the BAP. For instance, there may be circumstances in which the WFD categorisation of 'heavily modified water body' (where ecological 


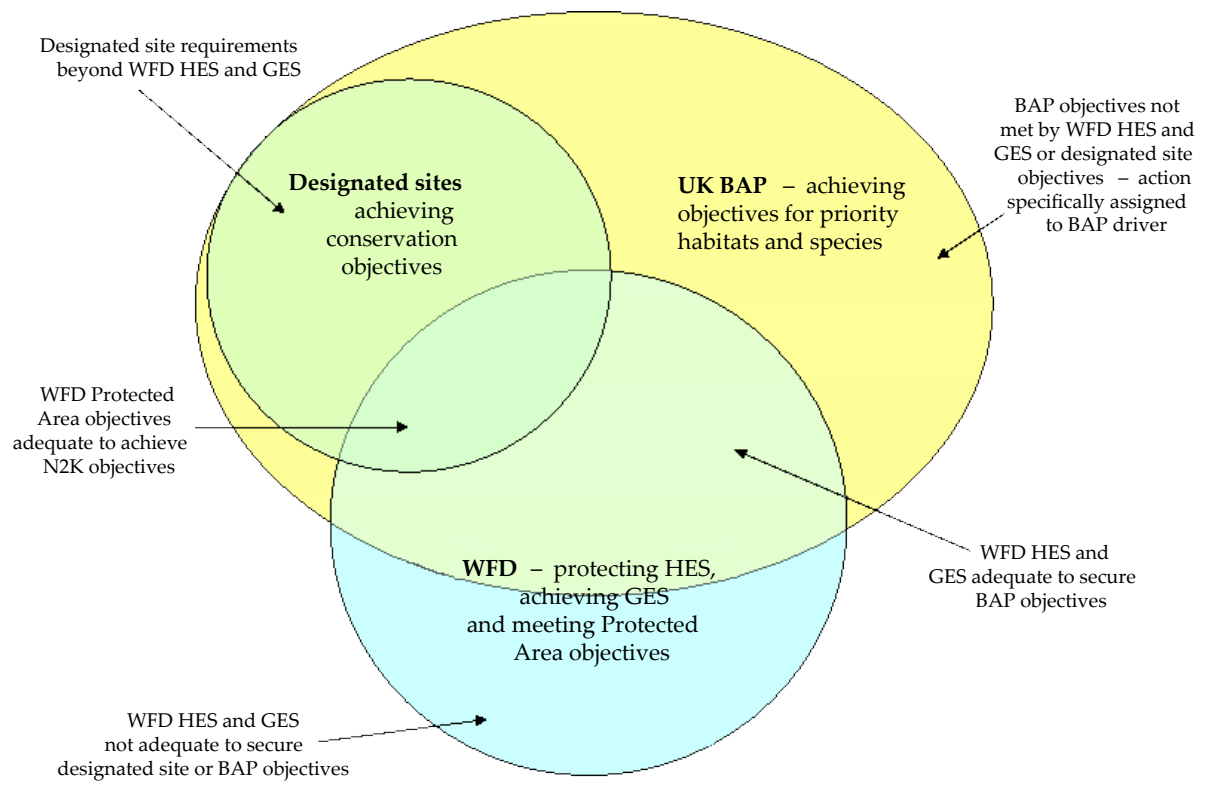

Fig. 1. Interactions between key policy drivers in the water environment. $B A P=$ Biodiversity Action Plan, WFD $=$ Water Framework Directive, HES = High Ecological Status, GES = Good Ecological Status. N2K sites = Natura 2000 sites, comprising sites designated under the EC Habitats and Species and Birds Directives.

objectives can be formally relaxed to an unprescribed level caused by the essential human use of the water body) is used extensively in a way that inadequately accounts for UK BAP objectives, say in respect to physical habitat restoration. Perhaps the definition of GES might be revealed as inadequately protective of a particular rare BAP priority species in its specific habitat type, such that measures to achieve a higher level of ecological quality may be required to support the species in some locations.

\section{Designated freshwater sites and climate change}

Climate change has been heralded by some as 'the final nail in the coffin' for designated wildlife sites. It is certainly a major conceptual challenge - the historical rationale for site designation and management is based on an unwritten assumption that climate, although variable on short timescales, is stable over medium-term timescales relevant to management planning (though clearly not over geological timescales). This assumption is clearly inappropriate in the light of the evidence of climate change that is increasingly apparent every year and of climate change predictions for worse conditions to follow. In particular, the inclusion of species and specific biological communities as designated features of sites presumes that these sites will be capable of supporting these species and communities in future climate scenarios, which in many instances will not be the case.

The modification and integration of management strategies for designated sites and the wider environment in order to cope with the need for adaptation to climate change is a topic of intense debate within Natural England and more widely in the UK nature conservation agencies (e.g. Hopkins et al., 2007). There is a clear need for an ever-reducing reliance on species-based designations and species-based management objectives in designated sites in order to recognise both the inevitable changes in species distributions that will occur and to avoid inappropriate mitigation measures on sites that seek to maintain species outside of their changing climate space. A corresponding increased reliance on habitat designations and habitatbased management objectives will be required, focused on managing the level of anthropogenic stress on designated freshwater sites to maintain high quality habitat, however that might be altered by climate change. Species composition 
within sites will change and our success in maintaining our national species complement will depend on our ability to increase the suitability of the wider landscape to species most subject to change, providing a 'permeable' landscape within which movement to suitable habitats (whether designated or not) is possible. For freshwater communities, species movement occurs through aquatic, aerial and terrestrial routes and each of these routes will need strategic consideration - semi-natural river corridors with good longitudinal hydrological connectivity (no instream barriers to movement) are of critical importance.

In the designated freshwater site network in England, a strong emphasis is placed on habitat designations and habitat-based management objectives, despite site designations frequently including some species (often to fulfil the requirements of European Directives). Management objectives for freshwater sites are based largely on the control of anthropogenic effects on environmental conditions, rather than biological descriptions of the condition of species and communities. In some senses, the general management approach to designated freshwater sites is, therefore, preadapted to climate change. There is considerable work to do, however, to understand the probable nature and extent of species- and communityshifts that arise from climate change, in order to facilitate, manage and interpret necessary biological movements. The science of ecological connectivity in the landscape, specifically in the context of freshwater communities (e.g. Pringle, 2001), will be key to successful adaptation.

\section{Establishing strategic R\&D in fresh waters}

The immediate demands of the WFD have shortened the time horizons of much freshwater science within the UK and across Europe, moving the focus away from processbased experimental research to data mining, passive survey and the rapid generation of pragmatic ecological assessment tools. This pressure has been inevitable and the results have not been wholly uninformative, but it is time to look up from this work and bring a balance and longer-term perspective back to freshwater research.
The characterisation and quantification of key ecological processes in different freshwater habitat types and subtypes, associated with major pressure gradients such as eutrophication, siltation, abstraction stress and physical habitat degradation, have been neglected. The first management planning cycle of the WFD is the period in which this situation could be, and should be, rectified, with experimental designs that exploit concerted strategic action on these pressures within the catchments of designated wildlife sites.

A major programme of research is required, necessitating the close collaboration of major funders with a stake in a robust and objective science base to freshwater management. The new strategy of the Natural Environment Research Council (NERC, 2007), centred on a restructured Centre for Ecology and Hydrology, has a strong focus on partnership working and is to be warmly welcomed. In addition, freshwater researchers and the statutory environmental and conservation agencies in the UK have shown a willingness to find common ground in their research aspirations under the umbrella of a Cooperative Research Partnership in freshwater ecology, as proposed by Battarbee et al. (2006). Despite, or perhaps because of, the downturn in public sector funding streams and the consequent urgent need to pool resources, I would like to think that the scene is set for a new era of energetic scrutiny of the freshwater environment that is focused on developing a sound understanding of the management needs of UK freshwater biodiversity.

\section{Closing remarks}

Society needs the courage to take a truly strategic approach to freshwater management, to realise the multiple environmental and societal benefits that such an approach generates, to be honest and open about the affordability of such an approach, and to be realistic about the timescales over which this approach can be implemented. Governmental obligations towards designated wildlife sites provide the additional push that can make this vision happen. To achieve this scenario, however, we need a 
common vision of the strategic importance of these sites and their pivotal role in the future of freshwater management.

\section{References}

Battarbee, R., Hildrew, A., Jenkins, A., Jones, I., Maberly, S., Ormerod, S., Raven, P. \& Wilby, N. (2006). A Review of Freshwater Ecology in the UK. Freshwater Biological Association, Windermere. $22 \mathrm{pp}$.

Boon, P.J. (1991). The role of Sites of Special Scientific Interest (SSSIs) in the conservation of British rivers. Freshwater Forum 1, 95-108.

Hopkins, J.J., Allison, H.M., Walmsley, C.A., Gaywood, M. \& Thurgate, G. (2007). Conserving biodiversity in a changing climate: guidance on building capacity to adapt. DEFRA (Department for Environment, Food and Rural Affairs), London. $26 \mathrm{pp}$.

JNCC (1989). Guidelines for the Selection of Biological SSSIs. Joint Nature Conservancy Council, Peterborough. Available at: http://www.jncc.gov.uk/page-2303

Mainstone, C.P. \& Clarke., S.J. (in press). Managing multiple stressors on sites designated for freshwater wildlife - the concept of Limits of Liability. Freshwater Reviews.

McLeod, C.R., Yeo, M., Brown, A.E., Burn, A.J., Hopkins, J.J., \& Way, S.F. (eds) (2005). The Habitats Directive: Selection of Special Areas of Conservation in the UK. 2nd Edition. Joint Nature Conservation Committee, Peterborough. Available at: www.jncc.gov.uk/SACselection

NERC (2007). Next Generation Science for Planet Earth: NERC Draft Strategy: 2007-2012. Natural Environment Research Council. Available at: http://www.nerc.ac.uk/publications/planetearth/2007/autumn

Phillips, A. (1996). The challenge of restoring Europe's nature and landscapes. International Planning Studies 1, 73-93.

Pringle, C. (2001). Hydrologic connectivity and the management of biological reserves: a global perspective. Ecological Applications 11, 981-998.

Ratcliffe, D. (1977). A Nature Conservation Review. Cambridge University Press.

UKBAP (2007). UK List of Priority Species and Habitats. Available at: http://www.ukbap.org.uk/newprioritylist.aspx

Usher, M.B. (1989). Scientific aspects of nature conservation in the United Kingdom. Journal of Applied Ecology 26, 813-824.

\section{Author Profile}

Chris has 20 years of experience in freshwater ecology and the characterisation and control of anthropogenic impacts on freshwater habitats. He previously worked at the Water Research Centre until 1999 and then at English Nature until the formation of Natural England in 2006. Most of his time is currently taken up by work to improve the science underpinning conservation objectives for river SSSIs and SACs, the specification and implementation of measures to secure their favourable condition, and advising on riverine elements of the UK BAP and the Water Framework Directive. In the time left over he is helping to establish the UK Cooperative Research Partnership, which aims to bring researchers and research users closer together through the collaborative specification and funding of common-interest research. 